\title{
Perioperative risk stratification for a patient with severe obstructive sleep apnoea undergoing laparoscopic banding surgery
}

\author{
Laurence Weinberg, ${ }^{1}$ Stan Tay $^{2}$ Chung Fei Lai, ${ }^{1}$ Maree Barnes ${ }^{3}$
}

\begin{abstract}
${ }^{1}$ Department of Anaesthesia, Austin Hospital, Heidelberg, Victoria, Australia ${ }^{2}$ Department of Anaesthesia Royal Darwin Hospital, Tiwi, Northern Territory, Australia ${ }^{3}$ Institute for Breathing and Sleep, Austin Health, Heidelberg West, Victoria, Australia
\end{abstract}

\section{Correspondence to} Dr Laurence Weinberg laurence.weinberg@austin.org. au

\footnotetext{
To cite: Weinberg $L$, Tay $S$, Lai CF, et al. BMJ Case Reports Published online: [please include Day Month Year] doi:10.1136/bcr-2012008336
}

\begin{abstract}
SUMMARY
Summary Despite the increasing prevalence of obstructive sleep apnoea (OSA), there is limited evidence to guide appropriate preoperative investigations, inpatient or outpatient surgery allocation, and the anticipated level of postoperative care. With reference to our institution's perioperative risk stratification, we describe the case of a 46-year-old Caucasian male with a body mass index of $51 \mathrm{~kg} / \mathrm{m}^{2}$ admitted for laparoscopic band insertion. Management based on our guidelines involved a preoperative polysomnography where the patient was confirmed to have severe OSA. His postoperative care was then managed in the high dependency care unit. He was discharged home on day 2 with no further sequelae. We provide evidence that adoption of this model of care can simplify clinical decision making and resource allocation with favourable patient outcomes.
\end{abstract}

\section{BACKGROUND}

Although it is accepted that patients with obstructive sleep apnoea (OSA) are at increased perioperative risk for life-threatening airway obstruction, arterial oxygen desaturation and hypercarbia, clinical studies have not established a definitive causal relationship between OSA and adverse perioperative outcomes. There are no definitive data available to guide perioperative management of patients with OSA. ${ }^{1}$ Therefore, in the absence of definitive guidelines, risk stratification needs to be centred on each institution's patient demographics, incidence of airway complications, and the skill of medical staff in managing a difficult airway.

When evaluating patients with OSA who are to undergo surgery, three critical questions need to be considered in order to improve effectiveness of care in the keys areas of quality assurance and resource allocation. First, are additional preoperative investigations required to further assist in OSA risk stratification? Second, can the planned surgery be performed on an inpatient or outpatient basis? Finally, is a postoperative high dependency unit (HDU) (nurse to patient ratio of 1:2) or intensive care unit (ICU) (nurse to patient ratio of $1: 1$ ) bed required, or can the patient be allocated a general ward bed? A rational approach to perioperative OSA risk stratification can improve effectiveness of care in these key areas. We describe the risk stratification management of a patient with severe OSA for consideration of a laparoscopic gastric band insertion.

\section{CASE PRESENTATION}

A 46-year-old male with a body mass index (BMI) of $51 \mathrm{~kg} / \mathrm{m}^{2}$ (weight $150 \mathrm{~kg}$, height $1.71 \mathrm{~m}$ ) presented to our anaesthesia pre-admission clinic prior to an elective laparoscopic gastric band insertion. He had no other relevant medical history.

On presentation, his $\mathrm{O}_{2}$ saturation in room air was $94 \%$. He had no craniofacial abnormalities but had a neck circumference of $43 \mathrm{~cm}$. He also had a history of snoring with witnessed apnoeas. Biochemical and haematological laboratory investigations were normal. A recent echocardiogram revealed normal biventricular function with mild biatrial enlargement.

Given his history, a polysomnography was arranged. A diagnosis of severe OSA was made with an apnoea hypopnoea index of 41 and an $\mathrm{O}_{2}$ saturation nadir of $85 \%$. Continuous positive airway pressure (CPAP) was recommended and a therapeutic polysomnography prescribed a pressure of $13 \mathrm{~cm} \mathrm{H}_{2} \mathrm{O}$ with effective sleep efficiency (87\%). He remained compliant on this therapy up to the day of his surgery.

The plan for analgesia intraoperatively was multimodal using paracetamol $1 \mathrm{~g}$, ketorolac $30 \mathrm{mg}$, tramadol $100 \mathrm{mg}$ and local anaesthetic infiltration of the laparoscopic port wounds. Low dose opioids such as fentanyl were only to be used as rescue analgesia to minimise his sedation risk. However, the combination of his super-obesity (BMI $>50 \mathrm{~kg} / \mathrm{m}^{2}$ ) and severe OSA (compliant with CPAP) meant his perioperative clinical risk profile for airway complications was high. A HDU bed was therefore arranged for postoperative care.

\section{OUTCOME AND FOLLOW-UP}

The patient had an uneventful admission in HDU and was subsequently discharged home on the second post-operative day.

\section{DISCUSSION}

We report the use of a risk stratification algorithm for managing a patient with OSA undergoing a surgical procedure at our tertiary level hospital. Despite other published reviews discussing specific perioperative treatment strategies, ${ }^{1}{ }^{2}$ this algorithm addresses for the first time the key issues of preoperative testing, patient care and resource allocation. As with all guidelines, the use of this risk stratification model cannot guarantee any specific outcomes. ${ }^{1}$ Therefore, this model may be adopted, modified or rejected according to each institution's clinical needs and constraints. 
Figure 1 Risk stratification algorithm for patients with obstructive sleep apnoea (OSA) at our tertiary centre institution. BMl, body mass index; CPAP, continuous positive airway pressure; $F$, female; $G A$, general anaesthesia; $M$, male.

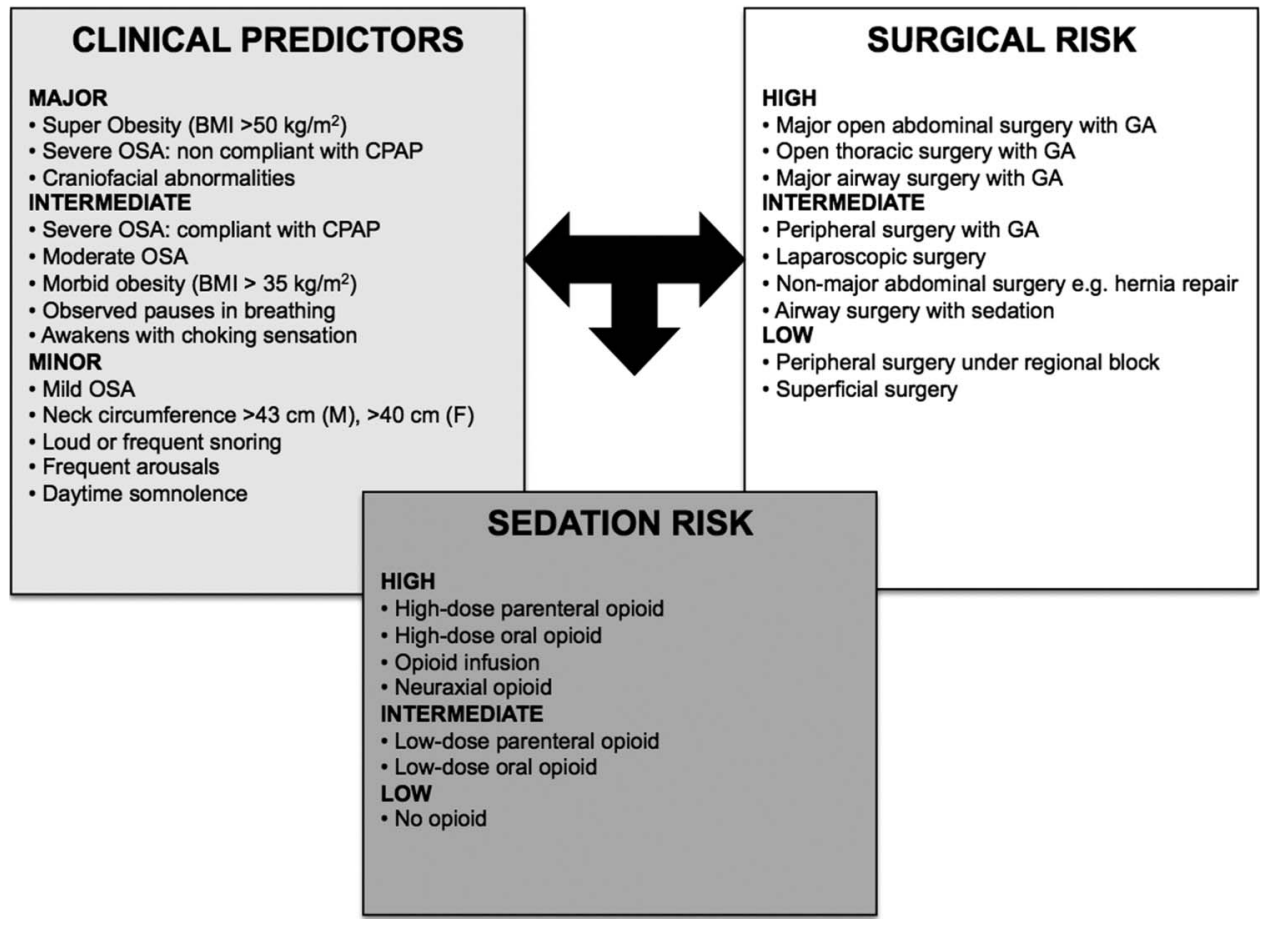

We based our risk stratification model for perioperative lifethreatening airway obstruction on three variables: clinical predictors, surgical factors and perioperative sedation risk (figure 1). We define the preoperative clinical predictors of OSA risk as major, intermediate or minor depending on the presence of obesity and/or the severity of OSA signs and symptoms. ${ }^{3}$ Major clinical predictors include severe OSA but poorly compliant with CPAP, super-obesity $\left(\mathrm{BMI}>50 \mathrm{~kg} / \mathrm{m}^{2}\right)^{4}$ and craniofacial abnormalities. ${ }^{5}$ Obesity itself profoundly alters pulmonary function and has adverse effects on respiratory mechanics. ${ }^{6-8}$ Intermediate clinical predictors include severe OSA based on sleep studies but compliant with CPAP, moderate OSA, morbid obesity $\left(\mathrm{BMI}>35 \mathrm{~kg} / \mathrm{m}^{2}\right.$ ), observed pauses in breathing, or awakening with a choking sensation. ${ }^{9}$ Minor clinical predictors are mild OSA, history of loud or frequent snoring, ${ }^{10} 11$ frequent arousals, large neck circumference $(>43 \mathrm{~cm} \text { male; }>40 \mathrm{~cm} \text { female })^{12-14}$ and neuro-behavioural dysfunction. ${ }^{9} 15$

For patients with OSA, we consider major surgery involving the abdomen, thorax or airway to be 'high-risk' for OSA complications (figure 1). Intermediate-risk surgery includes peripheral surgery under general anaesthesia, non-major open abdominal surgery (eg, hernia repair), laparoscopic surgery, and airway surgery with sedation. Low-risk surgery includes peripheral surgery with regional anaesthesia or local anaesthesia, and all superficial surgery. High perioperative sedation risk includes patients who require high dose parenteral opioids, opioid infusions, neuraxial opioids or high dose oral opioids in the perioperative period. ${ }^{16}$ Intermediate sedation risk includes the use of low dose parenteral or oral opioids. Low sedation risk includes patients who will not require opioids in the perioperative period.

The patient described in this case report had super-obesity and severe OSA compliant with CPAP. This placed him in the major risk category for clinical predictors (figure 1). He was undergoing laparoscopic surgery, and therefore his surgical risk was considered intermediate. The planned postoperative analgesic regime consisted of multimodal analgesia in combination with low dose opioids. Therefore his sedation risk was considered intermediate. Our decision-making strategy then for preoperative polysomnography was based on the result of risk stratification of the three variables (figure 2).

Several screening tools have been developed and validated to identify potential surgical patients with OSA: the Berlin questionnaire, ${ }^{17}$ the American Society of Anesthesiologists checklist ${ }^{1}$ and the STOP-Bang questionnaire. ${ }^{18}$ While these questionnaires have been validated as screening tools for OSA in the surgical population, ${ }^{19}$ formal preoperative testing with polysomnography in patients with clinical risk factors for OSA is still

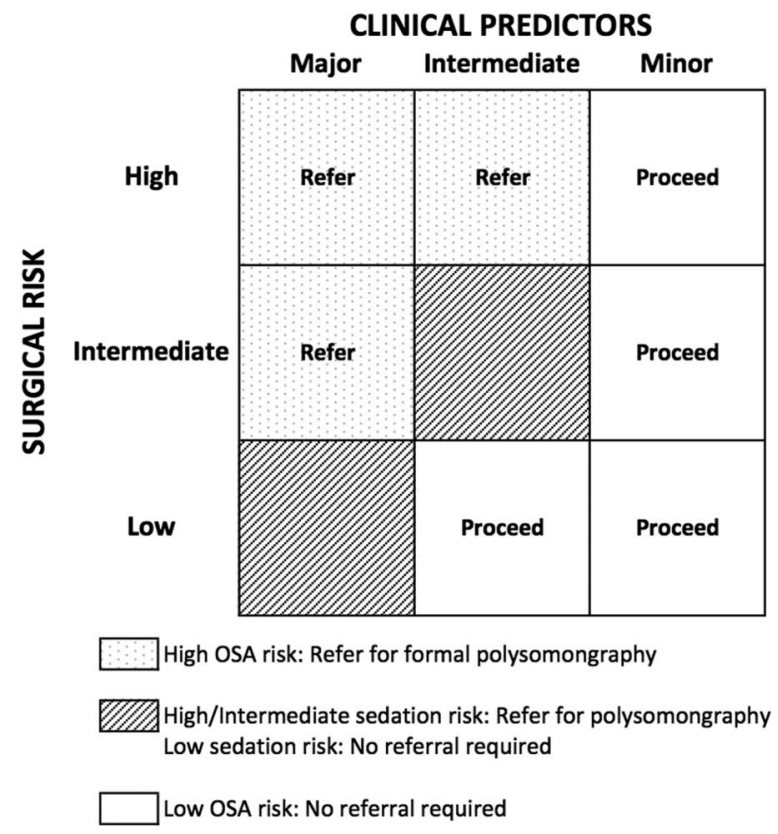

Figure 2 Preoperative referral process for diagnostic investigations for patients with obstructive sleep apnoea (OSA) at our tertiary centre institution. 


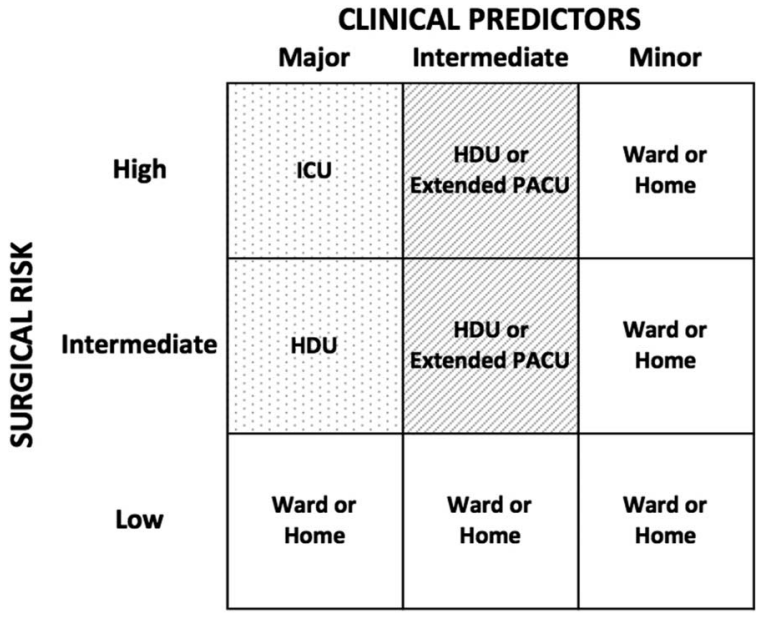

High OSA risk: Requires ICU or HDU bed

High risk: HDU bed

Intermediate/Low sedation risk: Extended PACU then ward

Low OSA risk: General ward bed or home is surgery allows

\section{ICU: Intensive Care unit; HDU: High Dependency Unit; PACU: Post} Anaesthesia Care Unit

Figure 3 Perioperative bed resource allocation for patients with obstructive sleep apnoea (OSA) at our tertiary centre institution. HDU, high dependency unit; ICU, intensive care unit; PACU, post anaesthesia care unit.

useful. $^{20} 21$ Although mandatory testing of all patients with OSA risk factors is recommended, limited facilities for testing in regional areas, long waiting periods in many sleep laboratories and the high cost of testing often limit the accessibility of this important diagnostic test as part of routine perioperative care.

If a diagnostic sleep study is recommended by our algorithm but cannot be obtained, we collaborate with the surgical team, intensive care and respiratory physicians to jointly decide whether to postpone surgery to obtain formal sleep studies or to pre-emptively initiate CPAP therapy. As outlined in figure 2, for patients with minor clinical predictors and for patients with intermediate clinical predictors undergoing low risk surgery, we do not advocate further preoperative testing. This is important in the key area of resource allocation. For patients with intermediate clinical predictors undergoing intermediate risk surgery and for patients with major clinical predictors undergoing low risk surgery, a low sedation risk also precludes further investigations.

We use a similar approach in deciding which patients should be offered a postoperative ICU, HDU or general ward bed (figure 3). This is important again from a resource allocation perspective. An ICU bed is reserved for all patients with major clinical predictors undergoing high-risk surgery. A HDU bed is reserved for patients with major clinical predictors undergoing intermediate-risk surgery. Bed allocation for patients with intermediate clinical predictors undergoing high- or intermediate-risk surgery depends upon sedation risk. Patients with an intermediate or low sedation risk are admitted to the post anaesthesia care unit for an extended period of $4 \mathrm{~h}$, and in the absence of airway complications, are then transferred to the general ward. All patients with minor clinical predictors and all patients undergoing low-risk surgery are discharged to the ward or home if surgery allows.

\section{Learning points}

- Surgery for patients with obstructive sleep apnoea poses significant challenges for the anaesthetist; however, use of a risk stratification model can assist in the management of these patients.

- Management involves directing the use of polysomnography, deciding whether the patient should undergo surgery as an inpatient or outpatient, and planning for the level of postoperative care required.

- Risk stratification algorithms can improve the effectiveness of care in the keys areas of quality assurance and resource allocation.

Competing interests None.

Patient consent Obtained.

Provenance and peer review Not commissioned; externally peer reviewed.

\section{REFERENCES}

1 Gross JB, Bachenberg KL, Benumof IL, et al. American society of anesthesiologists task force on perioperative management. Practice guidelines for the peri-operative management of patients with obstructive sleep apnea: a report by the American Society of Anesthesiologists task force on peri-operative management of patients with obstructive sleep apnea. Anesthesiology 2006;104:1081-93.

2 Adesanya AO, Lee W, Greilich NB, et al. Perioperative Management of Obstructive Sleep Apnoea. Chest 2010;138:1489-98.

3 American Academy of Sleep Medicine Task Force. Sleep-related breathing disorders in adults: recommendations for syndrome definition and measurement techniques in clinical research. The Report of an American Academy of Sleep Medicine Task Force. Sleep 1999;22:667-89.

4 Rajala R, Partinen M, Sane T, et al. Obstructive sleep apnoea syndrome in morbidly obese patients. J Intern Med 1991;230:125-9.

5 Johal A, Patel SI, Battagel JM. The relationship between craniofacial anatomy and obstructive sleep apnoea: a case-controlled study. J Sleep Res 2007;16:319-26.

6 Ahmad S, Nagle A, McCarthy RJ, et al. Post-operative hypoxemia in morbidly obese patients with and without obstructive sleep apnea undergoing laparoscopic bariatric surgery. Anesth Analg 2008;107:138-43.

7 Koenig SM. Pulmonary complications of obesity. Am J Med Sci 2001;321:249-79.

8 Zerah $F$, Harf A, Perlemuter $L$, et al. Effects of obesity on respiratory resistance. Chest 1993;103:1470-6.

9 Strollo PJ Jr, Rogers RM. Obstructive sleep apnea. N Eng J Med 1996;334:99-104.

10 Gentil B, Lienhart A, Fleury B. Enhancement of post-operative desaturation in heavy snorers. Anesth Analg 1995;81:389-92.

11 Dealberto MJ, Ferber C, Garma L, et al. Factors related to sleep apnea syndrome in sleep clinic patients. Chest 1994;105:1753-8.

12 Hoffstein V, Mateika S. Differences in abdominal and neck circumferences in patients with and without obstructive sleep apnoea. Eur Respir J 1992;5:377-81.

13 Davies RJ, Ali NJ, Stradling JR. Neck circumference and other clinical features in the diagnosis of the obstructive sleep apnoea syndrome. Thorax 1992;47:101-5.

14 Mortimore IL, Marshall I, Wraith PK, et al. Neck and total body fat deposition in nonobese and obese patients with sleep apnea compared with that in control subjects. Am J Respir Crit Care Med 1998;157:280-3.

15 Johns MW. A new method for measuring daytime sleepiness: the Epworth sleepiness scale. Sleep 1991;14:540-5.

16 VanDercar DH, Martinez AP, De Lisser EA. Sleep apnea syndromes: a potential contraindication for patient-controlled analgesia. Anesthesiol 1991;74:623-4.

17 Chung F, Ward B, Ho J, et al. Preoperative identification of sleep apnoea risk in elective surgical patients, using the Berlin Questionnaire. J Clin Anesth 2007:19:130-4.

18 Chung $F$, Yegneswaran $B$, Liao $P$, et al. STOP questionnaire: a tool to screen patients for obstructive sleep apnoea. Anesthesiol 2008;108:812-21.

19 Chung F, Yegneswaran B, Liao P, et al. Validation of the Berlin questionnaire and American Society of Anesthesiologists checklist as screening tools for obstructive sleep apnea in surgical patients. Anesthesiol 2008;108:822-30.

20 Haines KL, Nelson LG, Gonzalez R, et al. Objective evidence that bariatric surgery improves obesity-related obstructive sleep apnea. Surgery 2007;141:354-8.

21 Hallowell PT, Stellato TA, Schuster M, et al. Potentially life-threatening sleep apnea is unrecognized without aggressive evaluation. Am I Surg 2007;193:364-7. 
Copyright 2013 BMJ Publishing Group. All rights reserved. For permission to reuse any of this content visit http://group.bmj.com/group/rights-licensing/permissions.

BMJ Case Report Fellows may re-use this article for personal use and teaching without any further permission.

Become a Fellow of BMJ Case Reports today and you can:

- Submit as many cases as you like

- Enjoy fast sympathetic peer review and rapid publication of accepted articles

- Access all the published articles

- Re-use any of the published material for personal use and teaching without further permission

For information on Institutional Fellowships contact consortiasales@bmjgroup.com

Visit casereports.bmj.com for more articles like this and to become a Fellow 